\title{
La transdisciplinariedad como eje transversal de la docencia universitaria: un constructo transmetodológico contrarresistencia*
}

\author{
[Separata]
}

Recibido: 6 de diciembre de 2021

Aprobado: 8 de junio de 2021

Citar como:

Rodríguez, M. (2021). La transdisciplinariedad como eje transversal de la docencia universitaria: un constructo transmetodológico contrarresistencia. Análisis, 53(99). https://doi.org/10.15332/21459169.6333

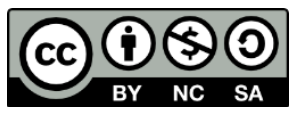

\section{Resumen}

La investigación rizomática desde la deconstrucción como transmétodo sustenta la transdisciplinariedad como eje transversal de la docencia universitaria, un constructo transmetodológico contrarresistencia, como objetivo complejo de investigación. Se deconstruye insubordinando las disciplinas en las universidades para interpelar al

\footnotetext{
* Artículo de investigación relacionado con la línea de investigación titulada: Educacióntransepistemologías transcomplejas.

** Cristiana Venezolana, PhD. en las nuevas tendencias y corrientes integradoras de pensamiento y sus concreciones, PhD. en Educación Matemática, Pensamiento y Religaje en la Transmodernidad, PhD. en Ciencias de la Educación, Dra. En Ciencias de la Educación, Dra. En Patrimonio Cultural, MSc. en Matemáticas, Licda. En Matemáticas, Docente Investigadora titular de la Universidad de Oriente, Departamento de Matemáticas. Correo electrónico:

melenamate@hotmail.com; ORCID: http://orcid.org/0000-0002-0311-1705
}

\section{Análisis}

ISSN: 0120-8454 | e-ISSN: 2145-9169 | DOI: https://doi.org/10.15332/21459169

Vol. 53 N.o 99 | julio-diciembre de 2021 
sujeto objeto en la docencia-investigación y, luego, en una reconstrucción esperanzadora, vamos a transversalizar la transdisciplinariedad en la docencia universitaria que anida una educación decolonial transcompleja, profundamente inclusiva que atiende a procesos complejos del ser humano y su conformación como ciudadano del mundo en una decolonialidad planetaria; la cual propende transmetodologías con transmétodos que complejizan los métodos, como la investigación transdisciplinar critica y la investigación acción participativa compleja.

Palabras clave: transdisciplinariedad, docencia universitaria, contrarresistencia, decolonialidad planetaria.

\section{Transdisciplinarity as a Transversal Axis of University Teaching: A Counter-Resistance Transmethodological Construct}

\section{Abstract}

Rhizomatic research from deconstruction as a transmethod supports transdisciplinarity as a transversal axis of university teaching, a counter-resistance transmethodological construct, as a complex research objective. It is deconstructed by insubordinating the disciplines in universities to question the individual object in teaching-research and, then, in a hopeful reconstruction, we will mainstream the transdisciplinarity in university teaching that lies in a transcomplex decolonial education, deeply inclusive that attends to complex processes of the human being and his shaping as a citizen of the world in a planetary decoloniality, which favors transmethodologies with transmethods that make complex the methods, such as critical transdisciplinary research and complex participatory action research.

Keywords: transdisciplinarity, university teaching, counter-resistance, planetary decoloniality. 


\title{
A transdisciplinaridade como eixo transversal do ensino universitário: um construto transmetodológico contra-resistência
}

\section{Resumo}

\author{
A pesquisa rizomática a partir da desconstrução como transmétodo \\ apoia a transdisciplinaridade como um corte transversal do ensino \\ universitário, uma construção transmetodológica contra-resistência \\ como objetivo complexo de pesquisa. Essa descontrução ocorre por meio \\ da insubordinação às disciplinas das universidades com o objetivo de \\ desafiar o sujeito objeto no ensino-pesquisa e, posteriormente, em uma \\ reconstrução esperançosa, vamos transversalizar a transdisciplinaridade \\ no ensino universitário que abrange uma educação decolonial \\ transcomplexa, profundamente inclusiva que atende aos processos \\ complexos do ser humano e sua conformação como cidadão do mundo \\ em uma decolonialidade planetária, que propõe transmetodologias com \\ transmétodos que complicam os métodos, como a pesquisa \\ transdisciplinar crítica e a pesquisa-ação participativa complexa. \\ Palavras chave: transdisciplinaridade, ensino universitário, contra- \\ resistência, decolonialidade planetária.
}

\section{Rizoma inicial. Necesidades de la docencia universitaria y transmetodología de la indagación}

Cuando nos referimos a la docencia universitaria las ciencias, divisiones departamentales, facultades, escuelas, entre otras parcelaciones, nos recuerdan la territoriedad física y el anclaje de poder de las disciplinas: intocables, colaborativas en visitas multidisciplinares al puerto frontera, pero muy poco transversalizadas y complejizadas. Parece un ejercicio personal, que al no cumplirse puede imponer sanciones conflictivas. De hecho, es un ejercicio de gestión manipulativa colonial, pero también 
personal como ejercicio de poder con lo que se cree conocer como definitivo e incambiable; excepto casos ejemplares dignos de engrandecer. El ser humano, docente-investigador, es dueño de su parcela a la que no están invitados los demás a menos de que exista una necesidad extrema; dentro de ese recinto inviolable el estudiante atiende y copia el estilo de la medicina tradicional cada vez más especializada. Siempre se dice esta parte o contenido no me corresponde, es de matemáticos, por ejemplo, este dice que hable el biólogo; aunque como autora matemática de años de ejercicios en las universidades: los matemáticos vamos más allá, aportamos a la solución de problemas de las otras ciencias, mal denominadas así. Pero los representantes de estas no nos invitan a quedarnos; damos muchos problemas, trastocamos con nuestra abstracción, interpelamos con los sistemas y con los fractales devotáramos el conocimiento en general. También la matemática debe indisciplinarse en la docencia-investigación y mostrar su verdadera esencia como ciencia, cuyo único apellido es la humanidad.

Desde luego, como pueden ver hay una crítica de la autora directa, con sus subjetividades y su experiencia; dirían los investigadores modernistas que la investigación es impersonal; no obstante, esto es mentira, así la quisieron hacer ver en su imposición Occidental modernistapostmodernista-colonial; acá en esta investigación transmetódica, más allá de los estatutos supervisados, vigilados e impuestos vamos a transcender los métodos y con el transmétodo, la deconstrucción rizomática en la transmodernidad; la investigadora es invitada, agente de cambio y sujeto subversivo de la interpelación, de lo no tocado; ella viene de religarse (Rodríguez, 2019a) de sus propios estatutos formativos modernistascoloniales.

Con dicho transmétodo, que explicitamos en breve, vamos más allá de las denominaciones: introducción, desarrollo, resultados, conclusiones, que 
han sido impuestas por todos lados; vamos con los rizomas, que tienen como esencia la multiplicidad, característica propia de una perspectiva rizomática, ya que esto implica que no hay un método y menos un camino único, por lo cual no se puede descalificar a priori, como posiblemente pase con las investigaciones coloniales; "los rizomas en construcción estimulan un pensamiento de la multiplicidad, en cuanto rechazo de un punto de origen" (Sicenore, 2017, p.91).

El rizoma dice, a la vez, que no existe ningún punto de origen o de principio primero que gobierne todo el pensamiento de la autora y de los autores interpelados; se hace por bifurcación, "encuentro imprevisible, reevaluación del conjunto desde un ángulo inédito; tampoco un principio de orden o de entrada privilegiada en el recorrido de una multiplicidad" (Zourabichvili, 2007, p.94). En esencia, está presente en tanto no nos debemos a los estatutos del síndrome de Introducción, metodología, desarrollo, conclusiones. Vamos más allá en un discurso de un complejo entramado.

La investigación se caracteriza como modelo rizomático (Deleuze y Guattari, 2004) en el sentido de crear sentidos intercomunicantes fértiles y desterritorializados que atienden aquellas realidades multidimensionales e interfásicas que transitan entre las operaciones racionales y las que corren de forma soterrada y simultánea por los subniveles, tales como: subconscientes, subpersonales, límbicos, paleocéfalos, egocéntricos, entre otros que atienden a las subjetividades de la autora (Bedoya, 2019). Todo ello, se va develando en la construcción total de la meseta investigativa conformada por los rizomas en cuestión.

Así se tiene que en la línea de investigación: educacióntransepistemologías transcomplejas, donde se encuentra la educación decolonial transcompleja (EDT) vamos a sustentar la transdisciplinariedad como eje transversal de la docencia universitaria, un constructo 
transmetodológico contrarresistencia como objetivo complejo de investigación. Es así como, la deconstrucción marca la indagación en un proyecto transmodernista descolonizador, pues deconstruir es también descolonizar (Rodríguez, 2019b). Se trata de un proceso complejo develador de la crisis de la docencia universitaria disciplinar, que incita a la transdisciplinariedad atravesando dicha docencia; es una urgencia transparadigmática que lleva a la transmetodología que de ninguna manera abandonan las disciplinas, ni los métodos, sino que los transcienden, complejizan y descolonizan para conseguir ricas esencias en el conocer y conformar al ser humano, su inclusión, condición humana y liberación. Se trata de saberes ecosóficos: arte de habitar en el planeta. Luego, iremos a una reconstrucción esperanzadora de la transdisciplinariedad en la docencia universitaria que, desde luego, permea la investigación: "deconstruir envuelve un acto creativo respaldado en la decisión, donde también se reconstruye, una reconstrucción esperanzadora que intercede en el discurso" (Rodríguez, 2019b, p. 1). Todo ello desde la educación decolonial transcompleja. ¿A qué nos referimos con educación decolonial transcompleja? Es un constructo que convoca a la enseñanza asumiendo una ecología de los saberes, minimizando el pensamiento abismal bajo las concepciones complejas y transdisciplinares, lo que salvaguarda los saberes de las civilizaciones encubiertas en el Sur, deconstruye la educación occidental impuesta: el locus occidental del saber y descoloniza todas las dominaciones en el ser humano y su educación.

Más adelante, desmitificaremos concepciones que por el mismo ir y venir de la indagación rizomática vamos manejando con mente-cuerpo-corazóny espíritu, la misma forma de desmitificarnos, desligarnos. Por ello, alertamos que la descolonialidad tiene sentido si es planetaria, si no cometeríamos los mismos errores de Occidente; jamás se debió contar con 
un Occidente sin un Sur respetado, valorado; pero jamás podemos comprender un Sur sin Occidente.

Como pueden ver ya en las motivaciones iniciales hemos comenzado una deconstrucción que seguimos develando en la crisis en el siguiente rizoma.

\section{Rizoma deconstrucción. Las disciplinas en las universidades: lo intocable en decadencia}

Queremos interpelar los territorios temáticos de la disciplinariedad en las universidades, atender a la premisa de que deconstruir es descolonizar (Rodríguez, 2019b). Para ello, debemos avizorar que, pese a los cambios curriculares, innovaciones, cambios de carreras y tecnologías, las universidades permanecen ancladas, salvo algunas excepciones, a las disciplinas. Más aún, esta es una de las aristas de la colonialidad de las mentes, el ser, hacer, pensar de sus docentes e investigadores.

De la misma manera, se desarrollan las investigaciones en las universidades con ligeras colaboraciones, pero no transdisciplinan en la mayoría de los casos; y hay un hecho clave en ello que debemos resaltar: ¿Dónde ha quedado el sujeto en las investigaciones disciplinares? el sujeto es aniquilado, a su vez, "para ser reemplazado por un número cada vez más grande de piezas separadas, estudiadas por las diferentes disciplinas. Es el costo que el sujeto debe pagar por un conocimiento de cierto tipo, que él mismo instaura" (Nicolescu, 2013, p.31). Este sujeto es tratado como objeto en las disciplinas, en esa realidad.

¿A qué se debe esta realidad? Una de las causantes son los ejercicios de poder en los que se cree que se tiene el conocimiento acabado y también a la falta de estimulación a investigar por parte del docente a sus estudiantes; en muchos de los casos, los docentes están formados en la investigación, pero no investigan su propia práctica, desconocen de estrategias metodológicas válidas para desarrollar saberes complejos. En 
la matemática acontece, por ejemplo, la descontextualización de asignaturas en la malla curricular de una carrera determinada, esto lleva a que el estudiante aprenda de una manera unidisciplinaria, truncando el conocimiento y comprimiendo las interconexiones que debe coexistir con su hábitat popular, las comunidades, cotidianidad, cultura (Estrada y Estrada, 2019).

Por otro lado, hace poco nombramos la frase locus occidental del saber (Mignolo, 2007, p.59). Este paradigma modernista cumplió, y sigue intentando homogeneizar la educación a favor de la producción de un ser humano ahistórico que regulariza su modo de ser, pensar, soñar, existir, producir, habitar y transcender a favor únicamente del sistema dominante instaurado, primero, con el colonialismo europeo, y ahora con el Norte y su imposición globalizadora.

La esencia decolonial de la EDT tiene sus cimientos en el extenso recorrido del pensamiento crítico-decolonial latinoamericano y hereda su esencia, ya que "es subversiva y antisistémica, teniendo una apertura constante a la interpretación crítica de la historia, lo que hace que esté en un constante diálogo de saberes e interesada profundamente en el accionar político" (Alvarado, 2015, p. 112). Se trata de un grito de liberación ontoepistemológica a la que asistimos convencidos de la necesidad de ello. Por otro lado, queremos, aprovechando la convergencia de la autora con las universidades venezolanas, describir parte de la crisis que afecta a la docencia-investigación y a todo el país. La crisis en Venezuela está dada en todos los aspectos, educativa, económica, de valores, del ciudadano y politiquera; esto se refleja en el emerger de universidades gubernamentales que coadyuvan a la crisis de formación con un claro propósito alienante, que develan las carencias que padecemos, aunado a la crisis de migración de actores de las universidades en general, sin menoscabar el saqueo y destrucción de las instalaciones de los recintos 
universitarios. La migración no es en búsqueda de un sueño mejor, es una huida en búsqueda de salvaguardar la vida y satisfacer las necesidades más básicas, pues en las universidades tradicionales teníamos el ejemplo notable de educar, en tanto de ello se dan cuenta algunos profesionales en el extranjero que marcan su pauta de preparación, y al mismo tiempo, las universidades venezolanas eran sitios de formación de profesionales extranjeros. Con esas realidades podemos decir que la pauta colonial y disciplinar se sigue padecido en las universidades venezolanas.

Aunado a la crisis descrita, está la inflación con salarios ínfimos que llevan al docente universitario a emigrar, trabajar informalmente en mercados mientras su salud peligra con un seguro social que no asegura ningún aspecto de la salud. Entretanto, quienes nos jubilamos, vemos como nuestras prestaciones han sido saqueadas con la destrucción de la moneda, la eliminación de ocho ceros que hace que una liquidación de jubilación tienda a cero mientras se sigue destruyendo el país con ataques permanentes al sistema económico, social y humano; esta situación permea la vida en su totalidad.

Se preguntarán: ¿Qué tiene que ver la crisis de las universidades venezolanas con toda la crisis del país? En primer lugar, quien le escribe, característica del transmétodo con sus subjetividades, es víctima del proceso que describe y declara que no está de acuerdo con violaciones al derecho constitucional, bloqueos, sanciones y mucho menos con golpes de estado; no lidero partidos políticos ni polarizaciones estériles que tanto daño han hecho, más ahora en tiempos de pandemia.

Quien le escribe es una de las profesionales activas en la investigación que ha colaborado a excelentes profesionales en la construcción de la labor universitaria de este país; vive y padece en Venezuela, le puede hablar con propiedad de cómo las universidades han sido denigradas y llevadas a su mínima expresión; mientras que en otras casas de estudios las autoridades 
universitarias permanecen inmóviles viendo de lejos la destrucción. El pueblo ha sido indolente al momento de defender la universidad donde se educaron sus hijos y el porvenir queda acéfalo y, de esa manera, sigue la ruina del país, que es la catástrofe de sus universidades, de su educación universitaria.

En segundo lugar, ahora les termino de responder la pregunta anterior más cercanamente a los hechos. Desde luego que la situación del país tiene que ver con la imposición, con la crisis curricular actual, porque ya contábamos con un currículo universitario que no se despojaba de los ropajes coloniales disciplinares; ahora él mismo entra en crisis y los currículos que se imponen en las universidades creadas del Gobierno actual pregonan descaradamente la ideología politiquera del momento, donde escasea la formación científica, académica seria y de nivel. Venezuela, con un currículo aun con rezagos coloniales, era un país con educación universitaria gratuita que graduaba profesionales en calidad y cantidad en el Sur del continente. Con profesionales que ahora con la migración disfrutan otros países y, en aquel entonces, con postgrados a los que personas de otros países podían acceder fácilmente.

Recientemente, de la Universidad de Oriente, ubicada en el Oriente venezolano, cubriendo cinco estados con cinco núcleos y varias extensiones, ha sido saqueada; los epistemicidios han llegado a sus bibliotecas quemadas, situación que ocurre en países en guerra; aquí ha ocurrido donde supuestamente no hay guerra. No obstante, yo opino que sí, estamos en la guerra por ver quién aporta más a la destrucción del país. En la indagación titulada Rasgadas las vestiduras en la Universidad de Oriente República Bolivariana de Venezuela (Lemus, et ál., 2020) se afirma que dejamos claro los tres autores de esta investigación, Udistas con gallardía, sembradores de amor en su recinto sus medallas en nuestro pecho, "en nuestro sentir la necesidad de ser atendidos por la comunidad 
nacional e internacional; a los que verdaderamente hace políticas educativas; a los que les duele Venezuela, su gente y han gozado de sus frutos" (Lemus, et ál., 2020, p. 26).

Por otro lado, de manera general, las tendencias en el Sur a crear docencias transdisciplinares no han dado los resultados deseados. ¿Está en tela de juicio la definición de transdisciplinariedad de mano de uno de los firmantes de la Carta de la Transdisciplinariedad del Primer Congreso de la Tansdisciplinariedad en 1994? una organización científica que procura ser una conciencia visionaria, transpersonal y planetaria, que se alimenta del crecimiento fabuloso del saber (Nicolescu, 1994) ¿Por qué hacemos esta pregunta? No estamos interpelando a las obras de Nicolescu Barasab, estamos abonando recursivamente de manera inversa, ¿̇por qué un concepto tan maravilloso como este no se ha llevado a la práctica como tanto urge? Porque ha podido el ejercicio de poder, la colonialidad de las mentes que hace mella en el ejercicio de la docencia e investigación.

Volvamos rizomáticamente al objetivo de la investigación: ¿Por qué decimos contrarresistencia en el objetivo complejo? Porque son bien conocidos los avances en materia de transdisciplinariedad en las universidades sobre todo en las investigaciones, pero ellos no han calado lo deseable en la praxis, salvo algunos casos ejemplares, desde luego; pero esta debe interpelarse, desligarse (Rodríguez, 2019a) de los rezagos coloniales que la encierran, pues es bien sabido que, en primer lugar, no toda transdisciplinariedad es decolonial. Debemos desmitificar la transdisciplinariedad de los rezagos de colonialidad que la postmodernidad le adoptó. Su esencia es liberadora.

Sí, estemos alerta, no toda transdisciplinariedad de la manera que se viene llevando a la práctica es decolonial "la descolonización epistémica envuelve variadas formas de transdisciplinariedad, pero no todas las formas de transdisciplinariedad son decoloniales" (Maldonado, 2015, p. 1). 
Ha sido elitizada la transdisciplinariedad y complejizada en visiones postmodernistas que siguen el cono de la modernidad en materia colonial. En esos rezagos y arrastres de modelos otros debemos estar alertas de desligarse para no seguir cometiendo los mismos errores.

En segundo lugar, porque los ejercicios coloniales en las universidades comienzan por las parcelas disciplinares que cada vez más se permutan en artefactos coloniales globalizadores y al no desligarse de las mentes coloniales, la educación suave colonial impuesta por el poder dominante y religarse a esencias liberadoras y, por tanto, inclusivas entonces se siguen cometiendo los mismos errores. Esto crea parcelas de enemigos en la docencia e investigación que se niegan a ser interpelados, a ser evaluados, mucho menos ser estudiosos y críticos de su propia praxis.

Así, la transdisciplinariedad en la docencia universitaria debe estar alerta y ser un ejercicio contrarresistencia decolonial en todo sentido, abarcando la gestión universitaria, alertando de la necesaria transgestión; más allá de las gestiones tradicionales de las universidades, la visión de la transgestión educativa de la EDT, es ir más allá de pisos paradigmáticos, no se asegura no volver a la problemática de manera incisiva, es la complejidad la que domina en pleno el discurso en un ir y venir.

Declaramos, entendiendo el ejercicio de la docencia universitaria, que está, la mayoría de las veces, enmarcada en la biopolítica del poder y que en la línea de investigación se profundiza en otras indagaciones; la biopolítica es "lo que hace entrar a la vida y sus mecanismos en el dominio de los cálculos explícitos y convierte al poder-saber en un agente de transformación de la vida humana" (Foucault, 2008, p. 135). Esa transformación debe permearse en la condición humana y en la responsabilidad como ciudadanos del mundo ante lo que debemos revisarnos y transformar en pensamiento profundo, religar el pensamiento desligándose de las viejas ataduras. 
Desde luego, este concepto corresponde a los puntos de encuentro y lo concerniente a lo biológico y lo político en la época contemporánea. ¿Estamos diciendo que el cuerpo se afecta con el ejercicio soslayador autoritario de un proyecto de dominancia con la educación universitaria? Sí, desde luego que sí; pues al afectar la psique del ser humano se afecta el cuerpo; considerando que el ser humano es cuerpo-mente-alma y espíritu, desde la complejidad se justifica que no se puede afectar uno de los componentes de la tetra sin afectar la otra; así, tenemos seres sumisos soslayados enseñando en la docencia universitaria y estudiantes atendiendo y copiando sin discernir.

El lector tradicionalista que no advierte esto puede desmitificar el valor de las líneas discursivas; por el contrario, quienes rompen con sus propios pisos paradigmáticos pueden abonar ricos aportes; es esa la esperanza, ies una esperanza viva! por un mundo mejor anidado en el nivel espiritual de lo que la Fe en Dios y su magnífica creación hace sentir, y de lo que la ecosofía se apropia desde la compasión, un profundo acto de amor que no minimiza al otro, como la lástima, sino que lo engrandece incitándolo a sacar lo mejor de sí y no bailar al ritmo de otros tambores, los de la desolación; de esta forma, se excluye solo lo que impide la inclusión con el abrazo del Norte y el Sur, en un ejercicio sensible a Occidente de nuestra cultura, de cómo salvaguardar el planeta, nuestros recursos. Podemos ser ejemplos para ellos, para eso debemos esforzarnos, develar nuestras potencialidades, encontrarnos y recrearnos en nuestra diversidad cultural (Rodríguez, 2020a).

La ecosofía categoría por excelencia, nos remite a religarnos en la docencia-investigación en las universidades, ir a la casa, el oikos, y la sophia, la sabiduría, para recivilizar. Urgen en las universidades la ecosofía, que va en la búsqueda de conciencia para sí y para los otros: "se ha convertido en una necesidad imperante de la educación. La búsqueda 
de esta conciencia hace que se profundicen aún más las necesidades de identidad tanto individual como planetaria para saber vivir y convivir juntos en una sola biosfera" (Molano, 2012, p. 7).

Vamos a una reconstrucción esperanzadora no definitiva, que converge en la transdisciplinariedad, en la docencia universitaria como insurgencia inclusiva.

\section{Rizoma reconstrucción. La transdisciplinariedad como eje transversal de la docencia universitaria: un constructo transmetodológico en resistencia de las prácticas hegemónicas}

Indisciplinar las disciplinas es un imperativo; se dice indisciplinar porque va en contraposición del proyecto modernista al enseñar las disciplinas de forma parcelada aislada del resto del conocimiento e inmerso en la disciplina que lleva la forma de hacer epistemológica, de hacer ciencia a la educación. Freire (1996) afirma que en la práctica educativa se da una educación bancaria, donde predomina la enseñanza repetitiva y castradora del pensamiento crítico, donde los protagonistas del acto de enseñanza no se regresan a la crítica de sus propias praxis, y es menester otro tipo de pedagogía en las instituciones educativas.

Es así como existe la necesidad de la consideración compleja en que las universidades se deben considerar organizaciones sociales complejas, estructuradas formalmente, donde la comunicación, el diálogo y la toma de decisiones atiende a los procesos de participación desde las individualidades grupales y colectivos de las ideas, necesidades, aportes y proyecciones en los procesos investigativos, que en este caso es fundamental insertarse en los aspectos, elementos, principios de la investigación transcompleja como eje dinamizador de cambios ecosóficos, 
como el arte de habitar en el planeta y las transformaciones de la sociedad transmoderna (Rodríguez, 2017).

Las universidades deben considerarse organizaciones sociales complejas, estructuradas formalmente, donde la comunicación, "el diálogo, la toma de decisiones atiende a los procesos de participación desde las individualidades, grupales y colectivos de las ideas [...] como eje dinamizador de cambios ecosóficos y transformaciones de la sociedad transmoderna" (Rodríguez, 2017, p. 128). Se trata de la conjunción universidades-comunidades que provean intersticios y salidas a los problemas reales que viven sus actores educativos.

Se trata desde estas perspectivas de la visión transdisciplinar e integradora de la cultura, y que debe estar presente en las concepciones de la transgestión educativa de la EDT. Es esencial la pertinencia del conocimiento producido, un conocimiento matemático sin aplicación no es un conocimiento, es importante y valioso si tiene utilidad, "si mejora las condiciones y sirve a la humanidad, muchos trabajos de investigación, con grandes conocimientos, no son conocidos por la comunidad, ni la sociedad civil, y son almacenados en bibliotecas" (Rodríguez, 2012, p.224).

Este es un ejercicio transdisciplinar ineludible que transversaliza la docencia universitaria: lazos afectivos-cognitivos-colaborativos; se trata del trabajo continuo en grupos transdisciplinares con personas diversas y de áreas de formación distintas, gesta vínculos de los miembros de la comunidad universitaria entre sí y luego de estos con la sociedad y comunidades (Pineau y Morín, 2007). De allí que el pedestal donde están erigidas las universidades como definitivas y con el saber último debe ser reconstruido y religado a un hacer comunitario-científico en el que conviven y se forman grupos que aprenden en cualquier lugar y tiempo con la diversidad cultural y cotidianidad. 
Es urgente el desarrollo de la condición humana como la dignidad y el punto fundamental de las relaciones transdisciplinares; se trata de aprender a expresarse y a escuchar a los demás y desenvolver actitudes de tolerancia y apertura ante otras personas y visiones, que les ayudan a lidiar con situaciones difíciles, a comprenderse y comprender a otros (Espinosa y Galvani, 2016). Todo ello, de la mano del dialogo-dialéctico como expresión metacognitiva, afectiva y de exploración del poder aprender en cada uno, el reconocerse con profunda fe en el otro.

Concretemos tales definiciones; el dialogo dialéctico está orientado a la “discriminación entre verdad y error mediante el pensamiento" (Panikkar, 1999, p.27); este tipo de diálogo parte de la hipótesis de que los participantes cooperan en una racionalidad, como el principio de no contradicción, y de ese modo pueden someter sus perspectivas a la audiencia de la razón; ello se pretende aplicar en los conceptos de la matemática y se conoce de los diálogos de Platón, Sócrates, entre otros. Panikkar (2003) declara que el diálogo dialéctico, si bien tiene su lugar en ciertos ámbitos de la vida humana, es insuficiente para asumir los retos de la interculturalidad. Así, en la educación, la comunicación es posible y debe ocurrir en un nivel diferente al de la dialéctica; pero desde luego no divorciada de ella.

Por ello, Panikkar (2003) va al dialogo dialógico y afirma que:

[...] en el diálogo dialógico somos conscientes de que los conceptos que utilizamos emergen de una fuente más profunda, donde me conozco y puedo conocer al otro, el diálogo dialógico no tiende, ni a la victoria en el contexto de las ideas ni a un acuerdo que suprima una auténtica diversidad de opiniones; dicho dialogo busca expandir el campo de comprensión con la profundización por parte de cada interlocutor de su propio campo de comprensión y la apertura. (Panikkar, 2003, p. 67) 
Como podemos ver, el diálogo dialéctico es sobre objetos, en este caso, matemáticos, sobre sus doctrinas, temas o problemas que se tratan en la ciencia; pero el diálogo dialógico es entre sujetos, entre docentes y discentes, porque el diálogo entre ellos en la educación es sobre ellos mismos y, de ese modo, consiguen entrar cada uno en el universo cultural del otro. Para ello, es imperativo considerar a la cultura desde lo cotidiano; cuestión que es posible en la descolonialidad planetaria, donde las ciencias y su educación toman en cuenta la complejidad y toda extensión de los aportes científicos inclusivos del Sur y de los países soslayados.

Es más, el diálogo dialógico asume un radical dinamismo de la realidad, esto es, "que la realidad no es dada de una vez para siempre, sino es real justamente por el hecho de que está continuamente creándose a sí misma y no simplemente desarrollándose a partir de premisas y puntos de partida preexistentes" (Panikkar, 1999, p. 38). ¿Cómo es posible este encuentro dialógico-dialéctico en la educación? Como se afirmó, el diálogo dialógico no se basa en la discusión de conceptos de las ciencias y educación, sino que utiliza como su instrumento los símbolos de la cultura científica. La diferencia entre concepto y el símbolo que lo representa es aquí esencial. Con ello vemos que en Panikkar (2003) es posible y necesario el diálogo dialéctico, así como el diálogo dialógico.

Por su lado, la emergencia de actitudes reflexivas de introspección, de autocrítica y la asunción de participar en diversos niveles de realidad, está también presente como una conciencia de sí. Se trata de la emergencia de una ética recursiva (Espinosa y Galvani, 2016). Dicha ética se traduce en la ética compleja que debe ir reformada en la docencia-investigación universitaria, lo que lleva a la necesaria inclusión con una visión que considere y aplique la ética compleja y sus tres elementos: autoética, socioética y antropoética; lo que conforma ciudadanos honestos y responsables en su forma de decidir y actuar cotidianamente para 
construir una vida personal y familiar auténticamente humana, profesionales capaces de caer en la cuenta de las implicaciones y compromisos de su acción profesional para la transformación radical de la sociedad en la que viven batallando la desigualdad y para la contribución a la mejora de la especie humana, la necesaria recivilización a través de la construcción de una tierra-patria profundamente inclusiva (López, 2015).

El proceso de enseñanza y aprendizaje universitario en la docencia universitaria con la transversalización de la transdisciplinariedad puede llevar a cambios significativos, en el ámbito epistémico para aprender a pensar complejamente la realidad a través de herramientas nuevas, a saber, los pilares transdisciplinares y los principios complejos (Morín, 2005; Nicolescu, 1998). Se trata de ir a transepistemes que, de acuerdo con el manifiesto de la transdisciplinariedad en lo decolonial, cumplen con los axiomas ontológico, lógico y epistemológico respectivamente emitido en el Manifiesto de la transdisciplinariedad; esto es: los niveles de realidad, el principio del medio incluido y la complejidad (Nicolescu, 1998).

De lo ontológico: los niveles de realidad en la transdisciplinariedad en la docencia universitaria de la EDT: "[...] se reconoce la existencia de diferentes niveles de realidad del objeto, y, en consecuencia, distintos niveles de realidad del sujeto" (Chávez, 2013, p.3). La transdisciplinariedad, así manifestada, es decolonial y consigue niveles de realidad entre las disciplinas que ellas no concebían por separado de las ciencias; también niveles de realidad entre las investigaciones cualitativas y cuantitativas en la EDT, donde lo cualitativo-cuantitativo-sociocrítico enriquece las conceptualizaciones en dicha enseñanza. Al mismo tiempo, que esos niveles se retroactúan, emergen nuevos niveles que se superponen y no se separan, muestran su esencia de mesetas, "estas emergieron de las más avanzadas ciencias contemporáneas, especialmente 
de la física cuántica, la cosmología cuántica y la biología molecular” (Nicolescu, 2013, p. 42).

Es menester volver sobre la crisis universitaria, preguntarse y responder sin ataduras disciplinarias: ¿qué es la realidad en la educación universitaria? Se trata de "lo que resiste a nuestras experiencias, representaciones, descripciones, imágenes o formalizaciones matemáticas" (Nicolescu, 1998, p. 17); es por esto por lo que la parcela de las disciplinas, en tanto que es la realidad, no existe. La realidad está por venir, por develarse, por estudiarse, introproyectar lo que se ha venido regularizando; así la realidad, tal como es, no ha sido estudiada.

Los niveles de realidad son "un conjunto de sistemas invariantes a la acción de un número de leyes generales" (Nicolescu, 1998, p. 18). El conocimiento complementario de los niveles de realidad es dinámico y está fuera de las ciencias a buscar lo ocultado y desvalorizado, a la educación en la ciudad (Freire, 1997) nuevos complementos que vayan delineando la complejidad de objeto transdisciplinario en la EDT.

Todo ello dice que los niveles de realidad no son únicos y que nos incita a seguir dirimiendo en busca de otros, y la matemática como permea a todos los saberes es especial para esos niveles o puntos de bifurcación y encuentros. Los niveles de realidad van confirmando lo que el objeto transdisciplinar decolonial en la EDT, "la unidad de los niveles de Realidad y su correspondiente zona complementaria de no resistencia constituye lo que llamamos el objeto transdisciplinario" (Nicolescu, 1998, p. 43). Ese objeto transdisciplinario de las ciencias debe ser presentado sin exclusiones o ataduras, sin preeminencias, esto es, decolonialmente. Del axioma lógico: la lógica del tercer incluido: referido a que el paso de un nivel de realidad a otro está asegurado por la lógica del tercero incluido (T)” (Chávez, 2013, p. 3), en cuanto se comprende a la lógica del tercero 
incluido o intermedios incluidos, como pilar de lo transdisciplinar decolonial.

Dos niveles adyacentes están unidos por medio de la lógica del tercero incluido, en el sentido de que el estado T presente, en cierto nivel, está ligado a un par de contradictorios (A, no-A) del nivel del vecino inmediato. El estado T opera la unificación de los contradictorios A y noA, pero esta unificación se opera a un nivel diferente de aquél donde están situados A y no -A”. (Nicolescu, 1998, p. 40)

En esto es en donde la realidad estudiada es discontinua y la posibilidad de los terceros incluidos proviene de realidades desvalorizadas en la modernidad. Por ello, el principio del tercero excluido ha creado una manera de "pensar binaria, que dicho sea de paso es la base de las demostraciones por reducción al absurdo, que, aunque consistente y fructífero en muchos sentidos, ha limitado nuestra comprensión del mundo" (Zamora, 2019, p. 70). Esa esencia apertura la ecología de los saberes, el dialogo son estudios en la EDT que están en pleno ardor en investigaciones.

El axioma epistemológico: la complejidad, el tercer pilar de la transdisciplinariedad: "da cuenta de que la estructura de la totalidad de los niveles de realidad es una estructura compleja, donde cada nivel es lo que es, debido a que todos los niveles existen al mismo tiempo" (Chávez, 2013, p. 3). Es la realización de la complejidad, la transdisciplina en la práctica, que atraviesa transversalmente mediante un dialogo de saberes. La esencia del objeto transdisciplinario decolonial en la EDT no es reducida, sino que lleva una continuidad de aportes de las ciencias cada vez más complementarias. La complejidad: se presenta con los rasgos inquietantes de lo enredado, de lo inextricable, del desorden, la ambigüedad, la incertidumbre, entre otras. De allí la necesidad, para el conocimiento, de poner orden en los fenómenos rechazando el desorden, 
de descartar lo incierto, es decir, de seleccionar los elementos de orden y de certidumbre, de "quitar ambigüedad, clarificar, distinguir, jerarquizar" (Morín, 2005, p. 17).

La transdisciplinariedad, entonces, converge en la práctica a la complejidad y va a conjugar saberes científicos-soterrados; estos últimos que no pasan por el filo de la cientificidad; así se conforman la ecología de los saberes con lo decolonial-transcomplejo minimizando el pensamiento abismal en lo separado por Occidente (Rodríguez, 2020b).

La creatividad como inmersión transdisciplinar no es mero hecho de innovaciones, no; la enseñanza de la creatividad también va acompañada del aprendizaje mediante la práctica y de proyectos transdisciplinares (Chanal, 2019), lo que transciende la gestión tradicional de las universidades hacia una transgestión, que desde luego es decolonial; las instituciones educativas deben estar a la altura de los problemas que la enseñanza propende, que exigen cambios de relevancia cuando el educador y el educando se unen en una meta y en una idea: el progreso intelectual, moral, espiritual y el cultivo de la conciencia de salvaguardar el legado del conocimiento por siglos de construcción y disfrute en sus creadores, en las futuras generaciones y prepararse para los tiempos venideros (Rodríguez, 2020a). Esto significa que las instituciones académicas tienen que establecer oportunidades de proyectos transversales y alentar a equipos transdisciplinares no solo de estudiantes, sino también de profesores, que necesitan aprender a trabajar juntos y poder guiar los proyectos de los estudiantes en campos en los que no son expertos.

¿Por qué sustentamos la transdisciplinariedad como eje transversal de la docencia universitaria, un constructo transmetodológico? Porque el conocimiento científico es un conocimiento que no se conoce en absoluto, que muta en las circunstancias, que se anida en rizomas y va formando 
mesetas que no terminan de emerger; así, la transdisciplinariedad necesita más allá de metodologías reduccionistas para anidarse, para ser lo más compleja y abarcadora posible, pues las metodologías tradicionales son la ciencia, de forma que no controlan su propia estructura de pensamiento: "el conocimiento científico es un conocimiento que no se conoce en absoluto [...] tan asombrosas y hábiles para aprehender todos los objetivos externos a ella, no dispone de ningún método para conocerse y pensarse a sí misma” (Morín, 1984, p. 37).

De allí que en los virajes y complejizaciones de los métodos hayamos desarrollado transmétodos que dan un viraje a las investigaciones en las universidades, proveyendo de complejos y sólidos rizomas para formar mesetas del conocimiento. Entre ellos, la deconstrucción rizomática que usamos en la presente investigación, la investigación transdisciplinar critica (Rodríguez, 2020c); esta es descolonizadora planetaria de los saberes; desde esta característica no hay centrismo en la producción del conocimiento transdisciplinar, sino multicentrismo, es decir, como estrategia, tomando en cuenta que en el conocimiento, los saberes en sí mismos no tienen sesgos, sino que los representantes de la disciplinas los sesgan y producen los centros (Rodríguez, 2020c).

También como transmétodo la investigación acción participativa compleja como transmétodo rizomático transcomplejo en la transmodernidad (Rodríguez, 2020d) es concientización e inclusión, alcanza desarrollos sociales, accionares profundamente políticos en las dimensiones social y política. El campo de estudio, incluyendo comunidades vírgenes en sus estudios, es un problema que en el develar decolonial urge salvaguardar; la reflexión de las pretensiones de inclusión no debe sesgarse a pretensiones algunas, sino la participación de los actores involucrados como los principales investigadores de su propia práctica desde una acción participativa (Rodríguez, 2020d). 
$\mathrm{Al}$ igual que en la deconstrucción, en el develar de la crisis queremos al final volver a Molano (2012) y la toma de conciencia que de la universidad debe erigir junto a las comunidades, las soluciones al problema de los países; la conciencia de la crisis mundial del planeta, de nuestras familias, la crisis política que no atiende al ciudadano, el develar y rasgarse las vestiduras en tiempos de encierro, de pandemia debe llevarnos a una nueva forma de accionar y de darnos cuenta de la necesaria toma de conciencia, de la reforma del pensamiento; la reforma de las mentes que propone Edgar Morín, la luciérnaga de la humanidad, es una reforma que viene clamando en sus obras. La que Dios amado en su palabra que alumbra habla en sus órdenes amarnos unos a los otros en ese necesario cambio, metamorfosis que urge en la humanidad.

Esta verdadera metamorfosis y no una careta de cambio debe hacerse teniendo como modelo perfecto a Jesús, nuestro salvador y no a modelos e ídolos del mundo, este está lleno de eso, el trabajo, la profesión, la familia, la sociedad entera. Debemos abandonar las etiquetas y comparaciones y, sobre todo, el juicio. Somos los hijos de Dios y sus promesas y actividades para nosotros están claros, no hay posibilidad de transformación si queremos compartir o tomar las funciones del Reino de Dios. A Dios, ser omnisciente, omnipotente y omnipresente le corresponden sus competencias de una manera perfecta como el gran Yo Soy (Rodríguez, 2020e). Para los ortodoxos que necesita justificar la palabra de Dios en las investigaciones les digo: Dios es el dueño, creador y mi Señor y es quien nos provee de sabiduría y ecosofía como parte del análisis, que está compuesta de la ecología espiritual, social y ambiental. Así, lo espiritual es agente contentivo del análisis.

El trabajo transdisciplinar de las universidades no estaría sustentado en la práctica si ellas no incitan e invita a las comunidades en sus lugares a religarse con los saberes científicos, a la aceptación de los saberes 
soterrados y su legitimidad; sin la transdisciplinariedad impregnada de la transversalidad como el saber cultural que es el centro menos incontaminado de la colonialidad; el centro de donde diverge la esencia del ser humano.

Para ello, las universidades no pueden seguirse erigiendo en el rey de los paradigmas, la simplificación, sino que deben ser centros de aperturas complejos religadores de su escueta formación y aporte a la humanidad; el universo de problemas debe devenir y convergen en soluciones complejas $\mathrm{y}$ transversales donde las universidades deben ser ejemplo de porvenir y calidad de vida ante el profesional. El estudioso que ingresa a sus instalaciones no puede seguir siendo el padecido en sus comunidades, donde las universidades, su centro de supuesta formación, permanece de espalda a su problemática de vida y aporta, en el caso venezolano, con servicios comunitarios de un semestre que escuetamente visitan el problema sin quedarse a cohabitar con él hasta solventarlo.

El centro de debate, entonces, debe salir del aula física de las universidades e irse a un aula mente-espíritu que es el espacio intersubjetivo de los actores de las universidades que se permean en todo momento y tiempo con todo su ser en los que emergen salidas y circunstancia en su complejidad de vida. El aula mente-espíritu es tema de la continuación de la línea de investigación mencionada. Pero adelantamos su análisis en tanto las universidades no están de espalda a la complejidad del ser humano, como aprenden. Querer permanecer inmóvil como su espacio físico es tener universidades apartadas de la vida del ciudadano en el que su vida jamás es transformada desde la formación en una disciplina; hay que indisciplinarla y subvertir el viejo papel disciplinar de las universidades.

La verdadera resistencia contrahegemónica de las universidades es subvertir la inhumanidad en la que viven sus actores, esa sería el 
verdadero grito y transformación, para hacer praxis al andar como Paulo Freire, la utopía del andariego que cada día transformó la realidad padeciendo con sus discentes y empoderándonos para transformar sus vidas. Bueno sería revivir su legado a punto de cumplirse cien años de su nacimiento en pleno 2021. Así, las universidades están en las comunidades en una verdadera investigación acción crítica participativa en el centro de los problemas donde la transformación de las vidas es urgente.

Hasta acá la sustentación que está en vías de reconstrucción día a día en el azaroso mundo de la descolonialidad, que consigue tentáculos y artefactos mutantes colonizadores que instan a desligarse y religarse en la conformación del ciudadano en las universidades.

\section{Rizoma final. Conclusiones de cierre en aperturas a la línea de investigación: educación-transepistemología transcompleja}

Hemos cumplido en la línea de investigación: educacióntransepistemologías transcomplejas, donde se encuentra la educación decolonial transcompleja, de sustentar la transdisciplinariedad como eje transversal de la docencia universitaria, un constructo transmetodológico contrarresistencia, como objetivo complejo de investigación. La deconstrucción que marcó la indagación es un proyecto transmodernista. La transdisciplinariedad en las universidades va a un cambio sustentado en el proyecto decolonial que anida un ejercicio de desligar y religar día a día con categorías como ecosofía, antropoética, condición humana, inclusión, entre otras. Estos nos incitan a dejar la trinchera de poder en la docencia, sin abandonar las disciplinas, pues sin ellas no existe transdisciplinariedad, sino que nos invita a complejizarnos y conseguir puentes de uniones en lo que el ser humano desliga la imposición 
occidental, que pongo separados por pensamientos abismales como el caso de los saberes soterrados y científicos.

Abogamos por saberes en general en las universidades, enriquecidos por la cientificidad, la historia y filosofía, el aporte de las comunidades

soterradas e invadidas, la cultura, cotidianidad y el hábitat popular. De esa cultura incontaminada donde está el mayor centro de resistencia contra la opresión del ser humano acondicionado a las elites económicas.

Al sustentar la transdisciplinariedad como eje transversal en la docenciainvestigación universitaria debemos estar atentos a los instrumentos de soslayación; en donde debemos llevar siempre una educación decolonial transcompleja sustentable, sostenible y cada vez más deconstructiva que mediante un ejercicio de amor político nos lleve a explorar mediante la fe en el ser humano sus mejores potencialidades; sus excelencias y proyectos de vida dormidos ante la sumisión y alienación.

Las Universidades del Sur deben ser ejemplo ante el Occidente y el Norte de la salvaguarda de nuestros recursos, de las comunidades van a las universidades y estas a las comunidades en una convergencia por la recivilización de la humanidad, pues ya sabemos que la crisis es de la civilización en la tierra-patria. Hay un disfrute en el desligar de sus propios fantasmas coloniales puestos en escena en una reconstrucción, religando su formación; de allí reconocemos lo que la humanidad ha perdido con execrar al sujeto investigador de las indagaciones.

Vamos también en contrarresistencia indisciplinando el hecho de querer continuar execrando las subjetividades de los sujetos en su propia formación, en la docencia e investigación; vamos con nuestras subjetividades a respetar la condición humana de los discentes, a converger en esencias del servicio al otro; vinimos a servir como el 
proyecto político más hermoso que se nos ha asignado a los seres humanos: ser verdaderos humanos.

En el cumplimiento del objetivo complejo, la creación de Dios en cada sentir, que atiende al amor como su primera excelsitud heredada del Padre Dios amado, le damos las gracias por su infinita sabiduría; en una complicidad especial ocurrida en esta investigación, donde siempre la gloria es de Dios en el nombre de Jesucristo. Así, "Y sobre todas estas cosas vestíos de amor, que es el vínculo perfecto" (Colosenses 3:14), "porque Jehová da la sabiduría, Y de su boca viene el conocimiento y la inteligencia" (Proverbios 2: 6).

\section{Referencias}

Alvarado, J. (2015). Pensar la educación en clave decolonial. Revista de Filosofía, 81, 103116. https://produccioncientificaluz.org/index.php/filosofia/article/view/21018

Bedoya, H. (2019). Los puntos ciegos de la transdisciplinariedad: una insuficiencia por subdisciplinariedad. Palabra, 19(1), 175-187. https://dialnet.unirioja.es/servlet/articulo? codigo $=7461161$

Chanal, V. (2019). La creatividad de la enseñanza en la educación superior: una perspectiva Comunitaria. Aula Abierta, 48(4), 407-418. https://doi.org/10.17811/rifie.48.4.2019.407-418

Chávez, M. (2013). Una teoría para la educación transdisciplinaria (Basada en el Manifiesto de Basarab Nicolescu). Revista Psicológica Herediana, 8, 1-10. https://revistas.upch.edu.pe/index.php/RPH/article/view/2944

Deleuze, G. y Guatari, F. (2004). Mil mesetas: capitalismo y esquizofrenia. PreTextos.

Espinosa, A. y Galvani, P. (2016). Transdisciplinariedad en la universidad: Experiencias en el Centro de Estudios Universitarios Arkos, México. Polyphonía, 27(1), 99-136. https://www.researchgate.net/publication/319051441 Transdisciplinariedad en la universidad Experiencias en el Centro de Estudios Universitarios Arkos $\underline{\text { Mexico }}$ 
Estrada, A. y Estrada, J. (2019). La investigación formativa desde la transdisciplinariedad, para la reforma del pensamiento dentro de la formación profesional. Uniandes Episteme, 6(2), 194-216.

http://45.238.216.13/ojs/index.php/EPISTEME/article/view/1288

Foucault, M. (2008). Historia de la sexualidad. 1. La voluntad de saber. Siglo XXI.

Freire, P. (1996). Política y Educación. Siglo XXI.

Freire, P. (1997). La Educación en la Ciudad. XXI Editores.

Lemus, J., Velásquez, A. y Rodríguez, M. E. (2020). Rasgadas las vestiduras en la Universidad de Oriente República Bolivariana de Venezuela. Revista Internacional de Pesquisa em Didática das Ciências e Matemática (RevIn), 1, e020018, 1-27. https://periodicoscientificos.itp.ifsp.edu.br/index.php/revin/article/view/202/111

López, J. (2015). Socioética y antropoética profesional para una educación universitaria contra la desigualdad. EDETANIA, 47, 17-38. https://dialnet.unirioja.es/servlet/articulo? codigo $=5348985$

Maldonado-Torres, N. (2015). Transdisciplinariedad y decolonialidad. Quaderna. http://quaderna.org/?p=418

Mignolo, W. (2007). La idea de América Latina. La herida colonial y la opción decolonial. Gedisa.

Molano, A. (2012). La complejidad de la educación ambiental: una mirada desde los siete saberes necesarios para la educación del futuro de Morín. Revista de Didáctica Ambiental, 11, 1-9. http://education.esp.macam.ac.il/article/653

Morín, E. (1994). Ciencia con consciencia. Anthropos.

Morín, E. (2007). Introducción al pensamiento complejo. Editorial Gedisa.

Nicolescu, B. (1994). Manifiesto de la transdisciplinariedad. Ediciones Du Rocher.

Nicolescu, B. (1998). La transdisciplinariedad, una nueva visión del mundo. Manifesto. Centro Internacional para la Investigación Transdisciplinaria (CIRET). Ediciones Du Rocher.

Nicolescu, B. (2013). La evolución transdisciplinaria del aprendizaje. Trans-pasando fronteras. Revista estudiantil de asuntos transdisciplinares, 4, 39-50.

https://www.icesi.edu.co/revistas/index.php/transpasando fronteras/article/view/1779

Análisis

ISSN: 0120-8454 | e-ISSN: 2145-9169 | DOI: https://doi.org/10.15332/21459169

Vol. 53 N.o 99 | julio-diciembre de 2021 
Panikkar, R. (1999). The Intrareligious Dialogue. Paulist Press.

Panikkar, R. (2003). El diálogo indispensable: Paz entre las religiones. Península.

Pineau, G. y Morin, E. (2007). Itinerario y obras de un autor transdisciplinario. Revista Visión Docente Con-Ciencia, 34, 5-14.

Rodríguez, M. E. (2012). El papel de la Educación Superior en la producción del conocimiento en el clima cultural del presente. REIFOP Revista Electrónica Interuniversitaria de Formación del Profesorado, 15(4), 119-125. https://revistas.um.es/reifop/article/view/174871

Rodríguez, M. E. (2017). La transgestión educativa transparadigmática en Venezuela. Praxis Educativa ReDIE, 9(17), 118-129. https://dialnet.unirioja.es/servlet/articulo? codigo $=6560027$

Rodríguez, M. E. (2019a). Re-ligar como práctica emergente del pensamiento filosófico transmoderno. ORINOCO Pensamiento y Praxis, 11, 13-3. https://zenodo.org/record/3709212

Rodríguez, M. E. (2019b). Deconstrucción: un transmétodo rizomático transcomplejo en la transmodernidad. Sinergias educativas, 4(2), 1-13. https://doi.org/10.31876/s.e.v4i1.35

Rodríguez, M. E. (2020a). La transgestión de la Educación Matemática Decolonial Transcompleja. En: (Coord.) H. Monárrez. Por el sendero de los transmétodos. (pp. 108-133). Instituto Universitario Anglo Español.

Rodríguez, M. E. (2020b). La ecología de los saberes en la Educación Matemática Decolonial Transcompleja. RCEF: Rev. Cien. Foco Unicamp, SP, 13, e020015, 1-18. https://econtents.bc.unicamp.br/inpec/index.php/cef/article/view/13731

Rodríguez, M. E. (2020c). La investigación transdisciplinar crítica: Un transmétodo rizomático en la transmodernidad. Perspectivas Metodológicas, 21, e3165, 1-9. https://doi.org/10.18294/pm.2020.3226

Rodríguez, M. E. (2020d). La investigación acción participativa compleja como transmétodo rizomático transcomplejo en la transmodernidad. Rev. Int. de Form.de Professores (RIFP), 5, e020026, 1-27. https://periodicoscientificos.itp.ifsp.edu.br/index.php/rifp/article/view/167/92 
Rodríguez, M. E. (2020e). La metamorfosis: sustentos rizomáticos desde las Sagradas Escrituras. Revista Hipótese, 6(1), p. 295-299, $2020 \mathrm{.}$ https://revistahipotese.webnode.com/edicao-021/

Sicerone, D. (2017). Rizoma, Epistemología Anarquista e Inmanencia en la filosofía de Deleuze y Guattari. Revista de Filosofía, 87(3), 83-94, 2017. https://dialnet.unirioja.es/servlet/articulo? codigo $=6453410$

Zamora, J. (2019). La transdisciplinariedad: de los postulados de Nicolescu al pensamiento complejo de Morín y su repercusión en el ámbito educativo. Revista Ensayos Pedagógicos, XIV (2), 65-82.

$\underline{\text { https://dialnet.unirioja.es/servlet/articulo? } \operatorname{codigo}=7211868}$

Zourabichvili, F. (2007). El vocabulario Deleuze. Editorial Atuel. 